\title{
Evaluation of smell disorders after radiotherapy in patients with laryngeal neoplasm
}

\author{
Mozes Huba', Gheorghe Muhlfay', Cristian Neagos', Adriana Neagos' \\ "George Emil Palade" University of Medicine, Pharmacy, Science and Technology, Otorhinolaringologic \\ Department, Targu Mures, Romania \\ 2"Carol Davila" University of Medicine and Pharmacy, Bucharest, Romania
}

\begin{abstract}
BACKGROUND. Smell disorders may be classified in quantitative and qualitative. The literature shows that the main causes of odour disorders, both qualitative and quantitative, are due to aging, viral infections and tumors of the upper respiratory tract, craniocerebral trauma, neurodegenerative diseases of the nervous system, drug use or exposure to various toxic substances. Total laryngectomy and oncologic treatment causes smell disorders.

OBJECTIVE. The aim of this study is to evaluate the aspects related to the patient's smell disorders after total laryngectomy, during the oncological treatment represented by radiotherapy.

MATERIAL AND METHODS. A prospective observational study was performed on a group of 52 patients, over a period of one year (2016-2017), who benefited from total laryngectomy and who underwent oncological treatment, represented by radiotherapy. Patients were evaluated before starting radiotherapy and during radiotherapy sessions. All patients underwent quantitative and qualitative smell assessment.
\end{abstract}

RESULTS. At the end of week 7 of radiotherapy, none of the patients was considered normosmic, 10 patients were considered to be suffering from hyposmia and 42 from anosmia. Statistically significant changes in the quantitative determination of odour occurred in the fourth week, respectively at the radiation dose of 40Gy. Qualitative odour assessment in this study showed a statistically significant decrease starting with the fifth week of radiotherapy, respectively with a radiation dose of 50Gy.

CONCLUSION. Radiation therapy has a major impact on the quality of life of patients with laryngeal cancer, which has the lowest scores at the beginning and end of the treatment.

KEYWORDS: smell disorders, laryngeal cancer, total laryngectomy, radiotherapy, anosmia, hyposmia.

\section{INTRODUCTION}

Smell disorders may be classified in quantitative and qualitative. Qualitative disorders are represented by the difficulty in identifying an odour (dysosmia), and may include parosmia. In some forms of qualitative odour disorders, patients perceive all odours as unpleasant, symptom known as cacosmia.

Quantitative disorders are hyposmia, reduction in odour perception, and anosmia, defined as the inability to perceive odours.

The literature shows that the main causes of odour disorders, both qualitative and quantitative, are due to aging, viral infections and tumors of the upper respiratory tract, craniocerebral trauma, neurodegenerative diseases of the nervous system, drug use or exposure to various toxic substances.

Laryngeal tumor pathology, lately with an increased incidence, dramatically changes the patient's quality of life, as a result of radical surgeries, followed by oncological treatments. The combination of surgical and oncological therapy, radiotherapy and chemotherapy, involves different therapeutic schemes, according to the protocols in force. Radiation therapy, along with chemotherapy, influences the body of the laryngectomized patient due to the side effects it pro- 


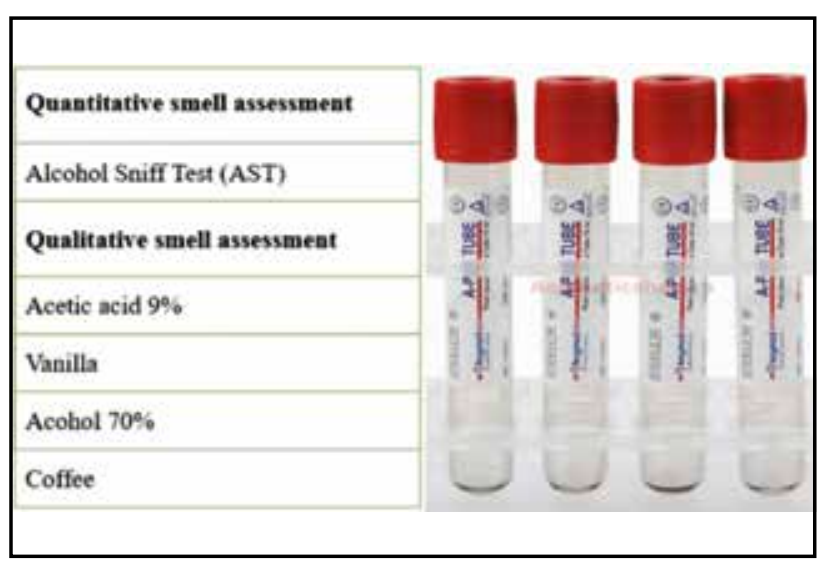

Figure 1. Olfactory assessment method by using test tubes containing different types of substances.

duces in the medium and long term. One of the effects is the odour changes in patients with laryngeal tumors, beneficiaries of surgical and oncological treatment.

Total laryngectomy causes smell disorders. The relationship between impaired sensory function, age, evaluated period and adjuvant treatment can be considered essential. Hyposmia is reported in the literature as the main odour change in patients undergoing oncological treatments ${ }^{1}$.

After the total laryngectomy, there is a change in airflow, due to the open tracheostomy. This compromises the contact of the nasal cavity and nasal mucosa with odorant molecules, which is reflected in smell disorders ${ }^{2,3}$. The change in the perception of smell in laryngectomized patients has as an explanation both for the disturbance of nasal respiration and the lack of mechanisms for its re-education.

Mucociliary clearance, an important nasal parameter, shows changes in laryngectomized patients with associated pathology, such as diabetics and former smokers. In the first phase after laryngectomy, there is a secretory increase, including in the nasal mucosal clearance, which can significantly influence the olfactory function ${ }^{4}$.

Complete separation of the airway after laryngectomy influences both the nasal cavity and the tracheobronchial airway.

Many studies confirm an impaired olfactory function in laryngectomized patients as a result of sensory damage caused by the interruption of nasal flow. However, a detailed highlighting of the involved structures related to changes in the olfactory mucosa is difficult to achieve ${ }^{5}$. Histological tests show frequent inflammation of the olfactory mucosa in patients without larynx. Total laryngectomy causes complete loss of smell, with a negative impact upon patient's standard of living and quality of life. In these patients, olfactory disorders are sometimes ignored ${ }^{6,7}$.
Nasal cytological analysis shows cellular metaplasia in laryngectomized patients. This is explained by the observation at the level of the inferior turbinate of a submucosal fibrosis as well as the presence of inflammatory infiltrates. All these have effects on smell ${ }^{8,9}$.

The aim of this study was to evaluate the aspects related to the patient's smell disorders after total laryngectomy, during the oncological treatment represented by radiotherapy.

\section{MATERIAL AND METHODS}

A prospective observational study was performed on a group of 52 patients, over a period of one year (2016-2017), who benefited from total laryngectomy and who underwent oncological treatment, represented by radiotherapy. The patients included in the study met the following criteria: total laryngectomy, confirmation of the histopathological diagnosis of laryngeal squamous cell carcinoma, post-operative radiotherapy. The exclusion criteria included: major cognitive impairment or a psychiatric or neurodegenerative disease, significant functional deficit, so that patients could not complete the evaluation questionnaire.

For the evaluation of the sense of smell, information was collected, such as: smoking or alcohol consumption, the type of surgery performed, oncological treatment, the period in which the tracheostomy was performed (if the tracheostoma was installed before or during surgery).

Patients were evaluated before starting radiotherapy and during radiotherapy sessions. In order to be able to study as accurately as possible and to include as many participants as possible, the evaluation was performed every week, for a period of seven weeks. The odour assessment test was performed once or twice a week at the beginning and end of the week.

To qualitatively assess the sense of smell, four specific odours were used: vanilla, coffee, acetic acid and alcohol. These substances are well known to all and could be easily recognized by an individual with a normal sense of smell. Each test tube contained $4 \mathrm{ml}$ of substance (Figure 1).

The Alcohol Sniff Test (AST) was used for the quantitative smell assessment. This test involves the use of diskettes impregnated with $70 \%$ isopropyl alcohol and one centimetre. The diskette is initially positioned $30 \mathrm{~cm}$ away from the nostrils. With each inhale, the diskette is positioned closer and closer to the patient's nasal cavity. The distance at which the patient smelled the substance is recorded. The procedure is repeated four times, with a one-minute break between evaluations. Accord- 


\begin{tabular}{|c|c|c|c|c|}
\hline \multicolumn{5}{|c|}{ 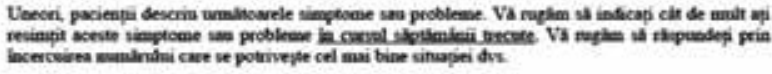 } \\
\hline In cursul siptaminil trecute: & Deter & Ratio & $\begin{array}{l}\text { Deinat } \\
\text { de enilt }\end{array}$ & $\begin{array}{l}\text { Fearte } \\
\text { malt }\end{array}$ \\
\hline 31. Ap mes daren la sivelud gain? & 1 & 2 & 3 & 4 \\
\hline 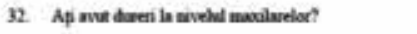 & 1 & 2 & 3 & 4 \\
\hline 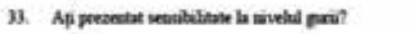 & I & 2 & 3 & 4 \\
\hline 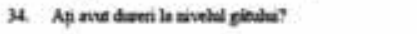 & 1 & 2 & 3 & 4 \\
\hline 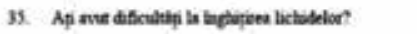 & 1 & 2 & 3 & 4 \\
\hline 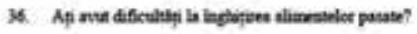 & 1 & 2 & 3 & 4 \\
\hline 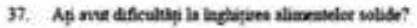 & 1 & 2 & 3 & 4 \\
\hline 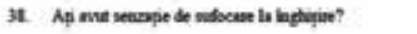 & 1 & 2 & 3 & 4 \\
\hline 99. Ap avit probleme au dingiv? & 1 & 2 & 3 & 4 \\
\hline 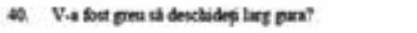 & 1 & 2 & 3 & 4 \\
\hline 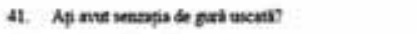 & 1 & 2 & 3 & 4 \\
\hline 42. Af mue walva lopicionily? & I & 2 & 3 & 4 \\
\hline 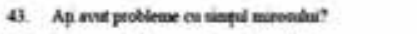 & 1 & 2 & 3 & 4 \\
\hline 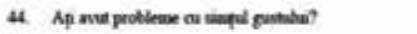 & 1 & 2 & 3 & 4 \\
\hline 45. Ap maint & 1 & 2 & $\mathbf{3}$ & 4 \\
\hline 46. Ap fost ribentex? & $\mathrm{t}$ & 2 & 3 & 4 \\
\hline 47. V-ap imptitue & $\mathrm{t}$ & 2 & 3 & 4 \\
\hline 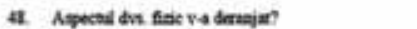 & 1 & 2 & 3 & 4 \\
\hline
\end{tabular}

Figure 2. Questionnaire to assess the quality of life in patients undergoing radiotherapy - EORTC QLQ-C30 HN35 Romanian version.

ing to the established scale, a patient with a normal sense of smell would be able to feel alcohol from $17 \mathrm{~cm}$ upwards, the one with hyposmia between 8 $\mathrm{cm}$ and $17 \mathrm{~cm}$, while the inability to feel the substance at a distance of less than $8 \mathrm{~cm}$ includes the patient in the category of anosmics. The quality of life was assessed using a questionnaire of the European Organization for Research and Treatment of Cancer - QLQ 30 (EORTC QLQ-C30) and the module for head and neck HN35 (Romanian version) (Figure 2). The data obtained from patients was processed using the SPSS 24 program.

\section{RESULTS AND DISCUSSIONS}

Before starting radiotherapy, from the total number of laryngectomized patients according to
Table 1.

Evaluation of patients with AST before and after radiotherapy.

\begin{tabular}{lll}
\hline Patients & \multicolumn{1}{c}{$\begin{array}{c}\text { Before } \\
\text { Radiotherapy }\end{array}$} & $\begin{array}{c}\text { At the end of } \\
\text { Radiotherapy }\end{array}$ \\
\hline Normosmic & $4(7.7 \%)$ & 0 \\
\hline Hyposmic & $24(46.15 \%)$ & $10(19.23 \%)$ \\
\hline Anosmic & $24(46.15 \%)$ & $42(80.77 \%)$ \\
\hline
\end{tabular}

the results of the Alcohol Sniff Test (AST), the following results were obtained: 4 patients were considered normosmic, 24 patients were hyposmic, the remaining 24 being diagnosed with anosmia (Table 1).

Radiation therapy has been performed for 7 weeks. At the end of week 7 of radiotherapy, none of the patients was considered normosmic and 10 patients were considered to be suffering from hyposmia. The majority of those included in the study - 42 patients - were diagnosed with anosmia (Table 1).

Qualitative odour testing showed a $92.3 \%$ decrease in the sense of smell in vanilla compared to the period preceding radiotherapy. The perception of acetic acid decreased by $77.7 \%$ in the seventh week, while the identification of alcohol decreased by $34.3 \%$ in the seventh week after starting radiotherapy compared to the period preceding it. The perception of the smell of coffee registered a decrease of $50 \%$ in patients between the two evaluated periods. The study shows a statistically significant change $(p<0.005)$ in the perception of vanilla starting with the fifth week when the radiation dose reaches 50Gy. For the other types of substances evaluated, statistically significant results are demonstrated only in the seventh week of radiotherapy, when the radiation dose reaches 70Gy (Table 2).

The quality of life registered the highest value in the fifth week after starting the radiotherapy, experiencing a gradual decrease towards the seventh week.

Table 2. Correlation between AST test and radiation dose.

\begin{tabular}{llllllll}
\hline & Week 1 & Week 2 & Week 3 & Week 4 & Week 5 & Week 6 & Week 7 \\
\hline AST & $\mathrm{p}=0.1107$ & $\mathrm{p}=0.104$ & $\mathrm{p}=0.062$ & $\mathrm{p}=0.004$ & $\mathrm{p}=0.001$ & $\mathrm{p}=0.003$ & $\mathrm{p}=0.001$ \\
\hline Radiation dose & $10 \mathrm{~Gy}$ & $20 \mathrm{~Gy}$ & $30 \mathrm{~Gy}$ & $40 \mathrm{~Gy}$ & $50 \mathrm{~Gy}$ & $60 \mathrm{~Gy}$ & $70 \mathrm{~Gy}$ \\
\hline
\end{tabular}


Problems related to the sense of smell are often neglected, given that the patient does not notice a decrease in odour ${ }^{7,10,11}$. The explanation given in this sense is the lack of re-education of nasal physiological respiration in patients with tracheal cannula. Radiation therapy has a detrimental effect on the olfactory function, adversely affecting the function of olfactory receptors ${ }^{12}$.

In the present study, statistically significant changes in the quantitative determination of odour occurred in the fourth week, respectively at the radiation dose of 40Gy (Table 2). Similarly, other studies have shown a decrease in the ability to quantitatively assess odour at the end of the radiation therapy ${ }^{13-15}$.

Recovery of the quantitative olfactory function was reported six months after treatment, but with a chaotic pattern, suggesting that olfactory cells can regenerate, but they are not fully functional ${ }^{15}$. Quantitative olfactory disorders were observed 20 months after completion of radiotherapy with a dose greater than $10 \mathrm{~Gy}$, as well as 5 years after treatment. The onset of other symptoms associated with treatment, such as rhinorrhea, may be a possible cause for the persistence of quantitative smell disorders 12 months after the end of treatment ${ }^{16}$.

Qualitative odour assessment in this study showed a statistically significant decrease starting with the fifth week of radiotherapy, respectively with a radiation dose of $50 \mathrm{~Gy}^{17}$. The result correlates with other studies, which highlight the appearance of smell disorders at the end of radiation therapy, especially in patients who received radiation doses higher than $10 \mathrm{~Gy}^{18,19}$.

Qualitative assessment of odour in patients, 2 weeks after the end of radiotherapy, revealed olfactory disorders especially in patients receiving doses higher than 20Gy. In contrast, when evaluating these patients at 12 months post-treatment, they demonstrated normal values for the identification of odorous substances ${ }^{20,21}$. The study led by Riva et al. pointed out that, 5 years after radiotherapy, there are no major changes in the qualitative identification of odour ${ }^{22}$. The explanation that can be given in this regard is precisely the re-education of nasal breathing in patients with tracheal cannula.

A study by Hahn et al. demonstrated that patients who were treated for laryngeal cancer with radiation therapy reported more frequently olfactory disorders at 6 months post-treatment than those who were treated without radiation therapy ${ }^{23}$. Surgery also plays an important role in the occurrence of olfactory dysfunctions, a study suggesting that patients who had partial or total laryngectomy experienced more olfactory disorders 5 years after the end of radiotherapy than those who had no surgery ${ }^{24,25}$.
There are several hypotheses investigating the role of radiation therapy in the occurrence of smell disorders. One possibility is that radiotherapy, at doses higher than 60Gy, slows down mitosis in basal cells, respectively the turnover of olfactory neurons is reduced ${ }^{26}$. Another cause of smell disorders may be a decrease in volume of the olfactory bulb due to radiation. A study in this regard showed that the volume of the olfactory bulb is significantly lower in patients who received radiotherapy compared to those who were not exposed to radiation ${ }^{24}$. Another hypothesis stated that smell disorders can be caused by the destruction of Bowman's glands by radiotherapy and by the replacement of the olfactory mucosa with the respiratory one ${ }^{23}$. Temporary demyelination of olfactory fibres or the destruction of enzymes in the olfactory mucosa are thought to lead to olfactory disorders. Another cause may be the appearance of an edema in the mucosa, which blocks the access of odorous substances ${ }^{26,27}$.

Impairment of central or peripheral pathways for the transmission of olfactory stimuli due to radiotherapy has been demonstrated in previous studies $^{28}$. Patients who have been treated with radiotherapy have a prolonged mucociliary clearance that leads to an increase in the frequency of upper respiratory tract infections and also to an increase in smell disorders ${ }^{29}$.

\section{CONCLUSIONS}

During radiation therapy, the olfactory function is affected beginning with the fourth week of radiation therapy and causes a substantial deterioration of smell, which persists even after cessation of treatment. The questionnaire EORTC QLQC30 and the head and neck module HN35 have proven to be effective and easy-to-administer tools for assessing patients' overall health status and quality of life.

Radiation therapy has a major impact on the quality of life of patients with laryngeal cancer, which has the lowest scores at the beginning and end of the treatment.

There is a need to develop new methods of rehabilitation of the nasal olfactory and respiratory function, as well as the application and education of patients in order to practice existing methods of smell restoration.

Conflict of interest: The authors declare that there is no conflict of interest.

Contribution of authors: All authors have equally contributed to this work. 


\section{REFERENCES}

1. Riva G, Sensini M, Corvino A, Pecorari G, Garzaro M. Smell and taste impairment after total laryngectomy. Ann Otol Rhinol Laryngol. 2017;126(7):548-54. DOI: 10.1177/0003489417709794.

2. Caldas ASC, Facundes VLD, Cunha DA, da Balata PMM, Leal LB, da Silva HJ. Gustatory and olfactory dysfunction in laryngectomized patients. Braz J Otorhinolaryngol. 2013;79(5):546-54.

3. van Dam FSAM, Hilgers FJM, Emsbroek G, Touw FI, Van As CJ, De Jong N. Deterioration of olfaction and gustation as a consequence of total laryngectomy. Laryngoscope.1999;109(7 Pt 1):1150-5.

4. Deniz M, Uslu C, Ogredik EA, Akduman D, Gursan SO. Nasal mucociliary clearance in total laryngectomized patients. Eur Arch Otorhinolaryngol. 2006;263(12):1099-104. DOI: 10.1007/s00405-006-0111-1.

5. Caldas ASC, Facundes VLD, Melo TMA, Dourado Filho MG, Pinheiro Júnior PF, da Silva HJ. Modifications and evaluation of smell and taste functions in total laryngectomy: systematic review. J Soc Bras Fonoaudiol. 2011;23(1):82-8. DOI: 10.1590/s2179-649120110001000017.

6. Miani C, Ortolani F, Bergamin Bracale AM, Petrelli L, Staffieri A, Marchini M. Olfactory mucosa histological findings in laryngectomees. Eur Arch Otorhinolaryngol. 2003;260(10):529-35. DOI: 10.1007/s00405003-0638-3.

7. Hamerlińska A. Applying nasal airflow - inducing maneuvers with patients with hyposmia after total laryngectomy. Contemp Oncol (Pozn). 2019;23(3):141-5. DOI: 10.5114/wo.2019.86688.

8. Skoloudik L, Vokurra J, Zborayova K, Celakovsky P, Kucera M, Ryska A. Cytology of the nasal mucosa after total laryngectomy. Acta Otolaryngol. 2009;129(11):1262-5. DOI: 10.3109/00016480802654398.

9. Karaca CT, Gültekin E, Yelken MK, Igdem AA, Külekçi M. Long-term histologic changes in nasal mucosa after total laryngectomy. Int J Otolaryngol. 2010;2010:137128.

10. Enriquez K, Lehrer E, Mullol J. The optimal evaluation and management of patients with a gradual onset of olfactory loss. Curr Opin Otolaryngol Head Neck Surg. 2014;22(1):34-41.

11. Wrobel BB, Leopold DA. Olfactory and sensory attributes of the nose. Otolaryngol Clin North Am. 2005;38(6):1163-70.

12. Hovan AJ, Williams M, Stevenson-Moore P, Wahlin YB, Ohrn KEO, Elting LS, et al. A systematic review of dysgeusia induced by cancer therapies. Support Care Cancer. 2010;18(8):1081-7.

13. Veyseller B, Ozucer B, Degirmenci N, Gurbuz D, Tambas M, Altun M, et al. Olfactory bulb volume and olfactory function after radiotherapy in patients with nasopharyngeal cancer. Auris Nasus Larynx. 2014;41(5):436-40. DOI: 10.1016/j.anl.2014.02.004.

14. Ophir D, Guterman A, Gross-Isseroff R. Changes in smell acuity induced by radiation exposure of the olfactory mucosa. Arch Otolaryngol Head Neck Surg. 1988;114(8):853-5.

15. Qiu Q, Chen S, Meng C, Liao F, Huang X, Li T. Observation on the changes nasopharyngeal carcinoma patients' olfactory before and after radiotherapy. Lin Chuang Er Bi Yan Hou Ke Za Zhi. 2001;15(2):57-8.

16. Brämerson A, Nyman J, Nordin S, Bende M. Olfactory loss after head and neck cancer radiation therapy. Rhinology. 2013;51:206-9. DOI: 10.4193/ Rhino12.120.

17. Álvarez-Camacho M, Gonella S, Campbell S, Scrimger RA, Wismer WV. A systematic review of smell alterations after radiotherapy for head and neck cancer. Cancer Treat Rev. 2017;54:110-121.

18. Risberg-Berlin B, Moller RY, Finizia C. Effectiveness of olfactory rehabilitation with the nasal airflow-inducing maneuver after total laryngectomy:one-year follow-up study. Arch Otolarynogol Head Neck Surg. 2007;133(7):650-4. DOI: 10.1001/archotol.133.7.650.

19. Olszewska E, Chodynicki S, Soroczynska J. Hearing disorders, dysosmia and dysgensia in patients undergoing irradiation for head and neck cancer. Otolaryngol Pol. 2002;56(3):297-301.

20. Holscher T, Seibt A, Appold S, Dorr W, Herrmann T, Huttenbrink K, et al. Effects of radiotherapy on olfactory function. Radiother Oncol. 2005;77(2):157-163. DOI: 10.1016/j.radonc.2005.09.015.

21. Ho WK, Kwong DLW, Wei WI, Sham JST. Change in olfaction after radiotherapy for nasopharyngeal cancer - a prospective study. Am J Otolaryngol. 2002;23(4):209-14. DOI: 10.1053/ajot.2002.123436.

22. Riva G, Raimondo L, Ravera M, Moretto F, Boita M, Potenza I, et al. Late sensorial alterations in different radiotherapy techniques for nasopharyngeal cancer. Chem Senses. 2015;40(4):285-92.

23. Hahn TR, Kruskemper G. The impact of radiotherapy on quality of life - a survey of 1411 patients with oral cancer. Mund Kiefer Gesichtschir. 2007;11(2):99-106. DOI: 10.1007/s10006-007-0049-5.

24. Landstrom FJ, Reizenstein J, Adamsson GB, von Beckerath M, Moller C. Long-term follow-up in patients treated with curative electrochemotherapy for cancer in the oral cavity and oropharynx. Acta Otolaryngol. 2015;135(10):1070-8.

25. Bindewald J, Oeken J, Wollbrueck D, Wulke C, Dietz A, Herrmann E, et al. Quality of life correlates after surgery for laryngeal carcinoma. Laryngoscope. 2007;117(10):1770-6.

26. Jalali MM, Gerami H, Rahimi A, Jafari M. Assessment of olfactory threshold in patients undergoing radiotherapy for head and neck malignancies. Iran J Otorhinolaryngol. 2014;26(77):211-7.

27. Hua MS, Chen ST, Tang LM, Leung WM. Olfactory function in patients with nasopharygeal carcinoma following therapy. Brain Inj. 1999;13(11):905-15. DOI: 10.1080/.26990599121106.

28. Galletti B, Santoro R, Mannella VK, Caminiti F, Bonanno L, De Salvo S, et al. Olfactory event-related potentials: a new approach for the evaluation of olfaction in nasopharyngeal carcinoma patients treated with chemo-radiotherapy. J Laryngol Otol. 2016;130(5):453-61. DOI: 10.1017/S0022215116000761.

29. Surico G, Muggeo P, Mappa L, Muggeo V, Conti V, Lucarelli A, et al. Impairment of nasal mucociliary clearance after radiotherapy for childhood head cancer. Head Neck. 2001;23(6):461-6. DOI: 10.1002/ hed. 1060 